\title{
Leber's Hereditary Optic Neuropathy in Women
}

\author{
W. A. FRANKS, and M. D. SANDERS \\ London
}

\begin{abstract}
Summary
Four women, from three families, are presented who developed severe bilateral optic nerve disease. A diagnosis of Leber's hereditary optic neuropathy (LHON) was made when male family members became affected. The disease ran a similar course in men and women with severe and permanent reduction in vision. Two women had been told that they suffered from multiple sclerosis. With recent advances in diagnostic techniques it should be possible to distinguish between these two conditions.

Although LHON may be underdiagnosed in women, there does seem to be a male preponderance of the disease in most European pedigrees.

Recent work supports the assumption that LHON is transmitted via cytoplasmic DNA; however, this does not explain why men are more likely to be affected, nor why only a minority of those carrying the defect develop the disease.
\end{abstract}

LHON typically presents as an acute optic neuritis occurring in both eyes within a few weeks of each other. ${ }^{1}$ Recovery occasionally occurs, but is rare, and most of those affected have severe visual loss. ${ }^{2,3}$ The diagnosis is usually made in adolescent males, but the condition also occurs in women, and may present at any age from five to 65 years. ${ }^{4,5,6}$ Abnormal vessels at the disc margin are found in patients and carriers and, when present, are diagnostic. ${ }^{7-10}$

The inheritance of LHON is unusual in that it is only transmitted through the female line. The pattern of inheritance has long been assumed to be due to transfer of a defect via cytoplasmic DNA from the maternal oocyte. ${ }^{11-14}$ Since spermatozoa have no cytoplasm, men cannot pass on the trait to their offspring.

Support for the theory of cytoplasmic inheritance has come from the finding of a mutation, a single amino acid substitution, in mitochondrial DNA, in nine of 11 families with LHON. ${ }^{15}$

We present three families in whom four women and four men developed LHON with a similar course and severity.

\section{Case Reports}

Family $A$ (Fig 1.)

Case 11a suffered bilateral visual loss at the age of 18 years during pregnancy. Her vision never recovered and no diagnosis was made. Her daughter, case $111 \mathrm{a}$, presented at the age of 25 years complaining of a disturbance of vision, firstly in the right eye, and four months later, in the left. Visual acuities of $6 / 60$ in either eye were recorded. Colour vision was impaired and visual field testing showed bilateral centrocaecal scotamata. Visual evoked responses were abnormal, with a normal electroretinogram. CT brain scanning was normal, as was examination of the cerebrospinal fluid, with no oligoclonal banding on protein electrophoresis. No visual recovery occurred, she was registered blind and the diagnosis given as multiple sclerosis. Four-

From The Department of Neuro-ophthalmology, The National Hospital for Nervous Diseases, Queen Square, London W1M 8BA.

Correspondence to: Wendy Franks F.R.C.S., F.C.Ophth., Moorfields Eye Hospital, City Road, London EC1V2PD 


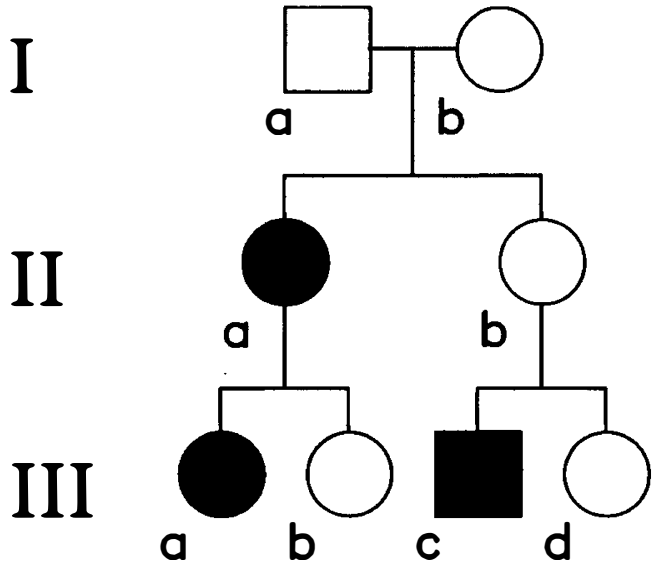

Fig. 1. Family $A$

teen years later there have been no further neuorological problems.

Her cousin, case $111 \mathrm{c}$, developed bilateral visual loss at the age of 29 , reducing vision to C.F. in each eye. He had bilateral central scotomata with loss of colour vision. MRI brain scan and cerebrospinal fluid examination were normal and a diagnosis of LHON was made.

Family $B$ (Fig 2.)

Case 11b developed disturbance of vision in the left eye at the age of 27 years. The eye had been amblyopic and vision had deteriorated from $6 / 24$ to $6 / 60$ with impairment of colour vision and a central scotoma. One month later vision in the right eye fell from $6 / 6$ to C.F. CT brain scan and examination of cerebrospinal fluid were normal. Treatment was commenced with ACTH but with no visual improvement. Over the next three years she com- plained of intermittent sensory disturbances of her hands and feet and was told that she suffered from multiple sclerosis. Genetic counselling was sought and she was told that the risk of blindness to her children was very low.

Two months after the birth of her son, her brother, case $11 \mathrm{c}$, at the age of 29 years, developed optic neuritis firstly in the left eye and two months later in the right, with features typical of LHON. $\mathrm{He}$ was registered blind with visual acuities of C.F. in the right eye and $4 / 60$ in the left. Their mother, who died at the age of 54 , had been adopted, and no further family history could be obtained.

\section{Family $C$}

Case 1a developed visual problems at the age of 8 years. The first records of ocular examination were 20 years later when she was found to have bilateral optic atrophy with visual acuities of $4 / 60$ in the right eye and $3 / 60$ in the left. No diagnosis had been made.

His grandson, case 111a, presented at the age of 19 years with sudden reduction in vision to $6 / 60$ in both eyes. Both optic discs were swollen with abnormal telangiectatic vessels at the disc margin, typical of LHON. CT brain scan and cerebrospinal fluid examination were normal.

Abnormal visual evoked responses and colour vision were recorded in two asymptomatic family members, $11 \mathrm{c}$ and $111 \mathrm{c}$.

Two years later, case 11a, who had not been previously examined, developed acute optic neuritis in the right eye at the age of 42 . Visual acuity fell to C.F. in the right eye and six months later the left eye became affected, reducing vision in that eye to C.F. Abnormal vessels at the disc margin were typical of LHON. MRI brain scan was normal although imaging of the optic nerve showed an increase sig-

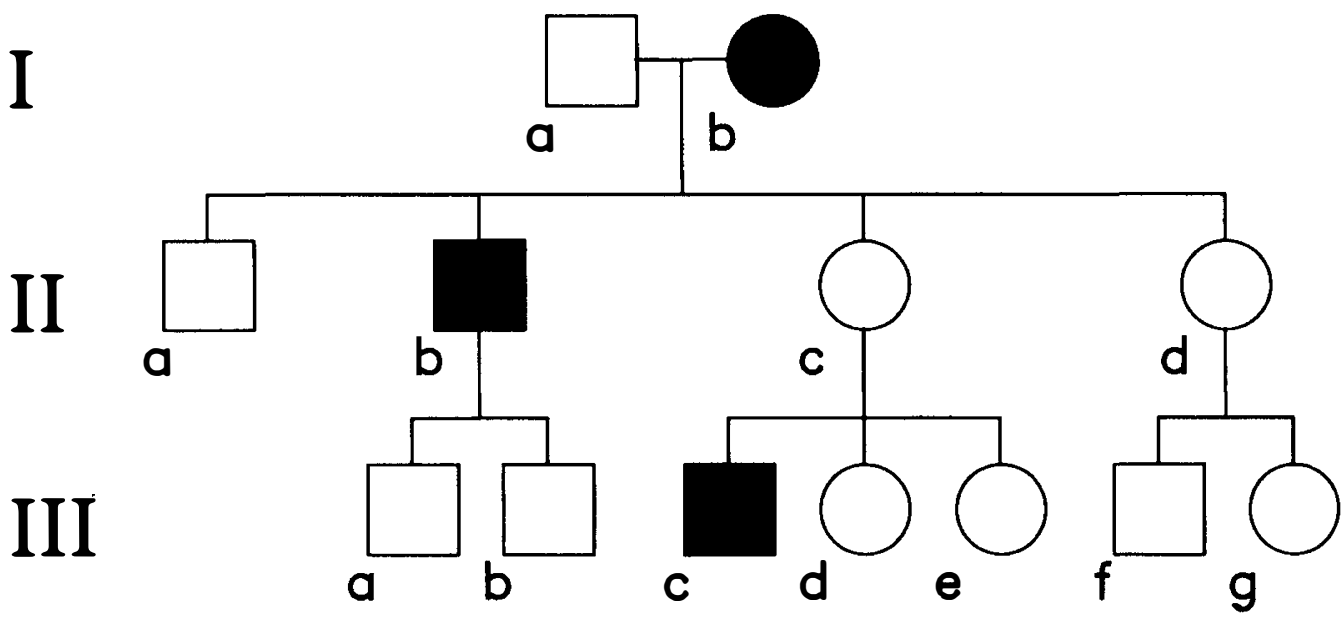

Fig. 2. Family $B$ 


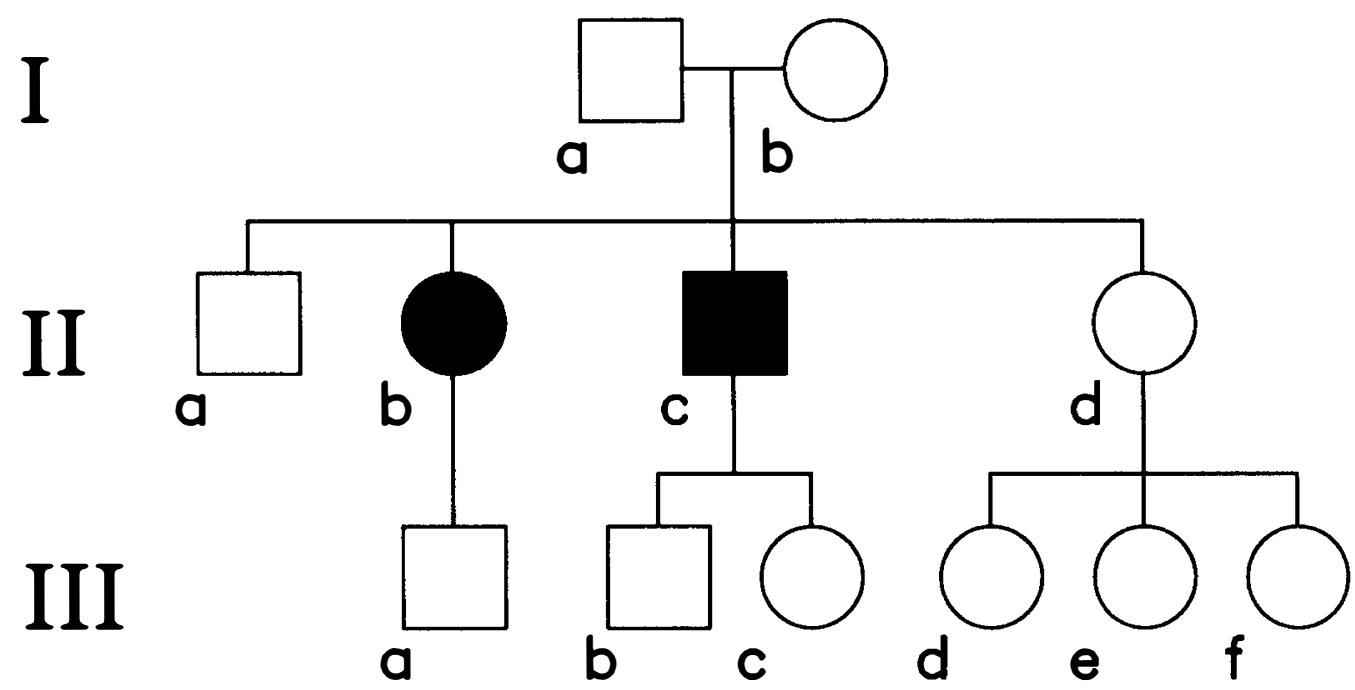

Fig. 3. Family $C$

nal in the posterior part of the nerve consistent with LHON.

\section{Discussion}

Several large pedigrees of LHON confirm that the condition is transmitted exclusively via the female line, although manifestation of the disease is commoner in men. The ratio of men to women affected varies widely between families, from $1: 1$ to $1: 20 .^{2,6,14,16,17}$ Although underdiagnosis in women may be a factor in the male preponderance of the disease, the condition does seem to be commoner in men in most European pedigrees.

Nikoskelainen studied 18 males and four females with LHON from a number of families with LHON and found that the average age at presentation was 37 years in women and 21 years in men. The age at presentation varied widely, with one female developing symptoms at the unusually late age of 63 years. ${ }^{9}$

The families presented here are small but are of interest in showing several well documented cases, so that the severity and course of the disease in men and women within families, can be compared. The age of presentation was similar in men and women, in families $\mathrm{A}$ and $\mathrm{B}$, in the late teens and twenties, but in family $\mathrm{C}$, was very wide, one female presenting at age eight years, her son at age 42 years, and grandson at age 18 years.
The disease ran a similar course in both sexes, with visual loss equally severe in men and women.

Some carriers of LHON have been shown to have abnormal colour vision and visual evoked responses and it has been suggested that this represents a mild form of the disease..$^{8,18,19}$

Bilateral optic neuritis without recovery is sufficiently unusual for the diagnosis of LHON to be considered whatever the age or sex of the patient. Three of the women had no family history of visual disturbance when they became affected, making diagnosis particularly difficult. However, the distinction from other cause of optic neuritis, particularly multiple sclerosis, is important both for prognosis and genetic counselling.

A positive diagnosis of $\mathrm{LHON}$ can be made on the fundus finding of telangiectatic vessels at the disc margin; however, these vessels are subtle and regress as the disease progresses. Fundus changes in asymptomatic maternal relatives is strong evidence in favour of LHON. ${ }^{8,9}$

MRI brain scanning is normal in patients with LHON, apart from an increased signal from the optic nerve, whereas in multiple sclerosis, lesions are commonly found throughout the white matter. ${ }^{20,21}$ Oligloclonal banding on protein electrophoresis of cerebrospinal fluid is found in $80 \%$ of cases of 
multiple sclerosis but is absent in LHON. ${ }^{22}$ Analysis of mitochondrial DNA by electrophoresis has shown loss of a DNA binding site in the majority of those tested, and promises to be a useful diagnostic test in the future. ${ }^{15}$

Cytoplasmic inheritance of the genetic trait does not explain the different sex prediliction of LHON and the genetic or environmental factors triggering the onset of the optic neuritis still elude us.

\section{References}

${ }^{1}$ Leber T: Ueber hereditaire und kongenital angelegte Sehnervenkrankenheiten. Graefe's Arch Ophthalmol 1871, 17: 249-91.

${ }^{2}$ Brunette $\mathrm{J}$ and Bernier RG: Study of a family with Leber's optic atrophy with recuperation. In Brunette J, Barbeau A (eds): Progress in Neuroophthalmology. Amsterdam; Excerpta Medica. 1969, p91-98.

${ }^{3}$ Constantine EF: Leber's disease with recovery. Arch Ophthalmol 1955, 53: 608-9.

${ }^{4}$ Friemann W: Erbliche Optikusatrophie bei frauen. Graefes Arch Ophthalmol 1949, 149: 266.

${ }^{5}$ Bell J: The Treasury of Human Inheritance. ed. Pearson K. Vol 2. Part 4. Cambridge University Press. 1931.

${ }^{6}$ Wallace DC: A new manifestation of Leber's disease and a new explanation for the agency responsible for its unusual pattern of inheritance. Brain 1970, 93: 121-32.

${ }^{7}$ Smith JL, Hoyt WF, Susac JO: Ocular fundus in acute Leber's optic neuropathy. Arch Ophthalmol 1973, 90: 349-54.

${ }^{8}$ Nikoskelainen E, Hoyt WF, Nummelin K: Ophthalmoscopic findings in Leber's hereditary optic neuropathy. Fundus findings in asymptomatic family members. Arch Ophthalmol 1982, 100: 1597-602.

${ }^{9}$ Nikoskelainen E, Hoyt WF, Nummelin K: Ophthalmosopic findings in Leber's hereditary optic neuropathy. The fundus findings in affected family members. Arch Ophthalmol 1983, 101: 1059-68.

${ }^{10}$ Nikoskelainen E: The clinical findings in Leber's hereditary optic neuropathy. Trans Ophthalmol Soc U.K. 1985, 104: 845-52.

${ }^{11}$ Imai Y and Moriwaki D: A probable case of cytoplasmic inheritance in man: A critique of Leber's disease. J Genet 1936, 33: 163-7.

${ }^{12}$ Ronne H: The inheritance of Leber's disease. Acta Ophthalmol 1944, 22: 203-14.

${ }^{13}$ Nikoskelainen EK, Sanontaus ML, Wayne OP, Katila MJ, Nummelin K: Leber's hereditary optic neuroretinopathy, a maternally inherited disease. Arch Ophthalmol 1987, 105: 665-71.

${ }^{14}$ Nikoskelainen EK, Hassinen IE, Paljarvi L, Lang H, Kalimo H: Leber's hereditary neuroretinopathy, a mitochondrial disease? Lancet 1984, ii: 1474.

${ }^{15}$ Wallace DC, Singh G, Lott MT, Hodge JA, Schurr TG, Lezza AMS, Elsas LJ, Nikoskelainen EK: Mitochondrial DNA mutation associated with Leber's hereditary optic neuropathy. Science 1988, 242: 1427-30.

${ }^{16}$ van Senus AHC: Leber's disease in the Netherlands. Doc Ophthalmol 1963, 17: 1-162.

${ }^{17}$ Lundsgaard R: Leber's disease: A genealogic, genetic and clinical study of 101 cases of retrobulbar optic neuritis in 20 Danish families. Acta Ophthalmol 1944, (Suppl 21): 1-306.

${ }^{18}$ Carrol WM and Mastalgia FL: Leber's optic neuropathy: A clinical and visual evoked potential study of affected and asymptomatic members of a six generation family. Brain 1979, 102: 559-80.

${ }^{19}$ Livingstone IR, Mastalgia FL, Howe JW, Aherne GES: Leber's optic atrophy: Clinical and visual evoked responses in symptomatic and asymptomatic members of a four generation family. $\mathrm{Br} \mathrm{J}$ Ophthalmol 1980, 64: 751-7.

${ }^{20}$ Jacobs L, Kinkel PR, Kinkel WR: Silent brain lesions in patients with idiopathic optic neuritis. Arch Neurol 1986, 43: 452-5.

${ }^{21}$ Johns K, Lavin P, Elliot JH, Partain CL: Magnetic resonance imaging of the brain in isolated optic neuritis. Arch Ophthalmol 1986, 104: 1486-8.

${ }^{22}$ Thompson CJ, Kaufoman P, Shortman RC, Rudge P, McDonald WI: Oligoclonal immunoglobulins and plasma cells in spinal fluid of patients with multiple sclerosis. Br Med J 1979, 1: 16-7. 